\title{
Use of the French healthcare insurance database to estimate the prevalence of exposure to potential drug-drug interactions
}

Cécile Souty ${ }^{1}$, Titouan Launay ${ }^{1}$, Olivier Steichen ${ }^{2,3}$, Cécile Conte ${ }^{4}$, Clément Turbelin ${ }^{1}$, Marianne Sarazin ${ }^{1}$, AnaMaria Vilcu $^{1}$, Louise Rossignol ${ }^{1,5}$, Thierry Blanchon ${ }^{1}$, Maryse Lapeyre-Mestre ${ }^{4}$, Thomas Hanslik ${ }^{1,6,7}$.

1. Sorbonne Université, INSERM, Institut Pierre Louis d'épidémiologie et de Santé publique (IPLESP UMRS 1136), Paris, France

2. Sorbonne Université, INSERM, Université Paris 13, Laboratoire d'informatique médicale et d'ingénierie des connaissances en e-santé, LIMICS, Paris, France

3. Assistance Publique - Hôpitaux de Paris (APHP), hôpital Tenon, Service de Médecine Interne, Paris, France

4. INSERM, Université de Toulouse (LEASP UMR 1027), Service de Pharmacologie médicale et clinique, CIC 1436, Centre Hospitalo-Universitaire de Toulouse (CHU Toulouse), Toulouse, France

5. Département de Médecine Générale, Université Paris Diderot, Paris, France.

6. Université de Versailles Saint-Quentin-en-Yvelines, UVSQ, UFR de Médecine, Versailles, France

7. Assistance Publique - Hôpitaux de Paris (APHP), hôpital Ambroise Paré, Service de Médecine Interne, Boulogne Billancourt, France

\author{
Corresponding author (Cécile Souty) \\ ORCID : 0000-0002-4990-5201 \\ IPLESP UMRS 1136
}

27 rue Chaligny, 75571 Paris Cedex 12 France

Keywords: Pharmacoepidemiology; Prevalence; Drug safety; Drug Interactions; 


\begin{abstract}
Purpose

Drug-drug interactions (DDIs) requires monitoring in an ageing population with increasing polypharmacy exposure. We aimed to estimate the prevalence of exposure to potential DDIs using the French healthcare insurance system database, for six DDIs with various clinical relevance: angiotensin II receptor blockers or angiotensinconverting enzyme inhibitors and nonsteroidal anti-inflammatory drugs (ARBs-ACEIs+NSAIDs), antiplatelet agents and NSAIDs (AAP+NSAIDs), serotonergic drugs and tramadol (SD+T), statins and macrolides (S+M), oral anticoagulant and NSAIDs (OAC+NSAIDs), colchicine and macrolides (C+M).
\end{abstract}

\title{
Methods
}

We used exhaustive healthcare data from a $1 / 97^{\text {th }}$ random sample of the population covered by the French health insurance system (EGB) between 2006 and 2016. Exposure to a DDI was defined as overlapping exposure to two interacting drugs. The prevalence of exposure was estimated by year.

\section{Results}

Prevalence of exposure in 2016 was estimated at $3.7 \%$ for ARBs-ACEIs+NSAIDs, $1.5 \%$ for AAP+NSAIDs, $0.76 \%$ for $\mathrm{SD}+\mathrm{T}, 0.36 \%$ for $\mathrm{S}+\mathrm{M}, 0.24 \%$ for AOC+NSAIDs and $0.02 \%$ for $\mathrm{C}+\mathrm{M}$. In $26 \%$ to $58 \%$ of episodes of exposure, the two interacting drugs were prescribed by the same physician and dispensed by the same pharmacy the same day. Between 2006 and 2016, the yearly prevalence was increasing for SD+T and for DDIs involving NSAIDs, and it was decreasing for those involving macrolides.

\section{Conclusion}

Exposures to potential DDIs in France are not uncommon with a high proportion resulting from a co-prescription by the same physician. Monitoring the prevalence of exposure to DDIs is needed to implement prevention measures. Administrative data enable this surveillance in large and representative cohorts. 


\section{Introduction}

Drug-drug interactions (DDIs) are a major concern in drug safety, accounting for 5\% to $26 \%$ of total drug-related adverse events [1, 2]. Two types of DDIs are described: pharmacodynamics and pharmacokinetics. Pharmacodynamics DDIs are linked to pharmacological properties of drugs on their target. Pharmacokinetics DDIs are defined as the modification of a drug on the absorption, distribution, metabolism, and excretion of another drug. DDIs can lead to an increase or a decrease in drugs activity and result in adverse drug reactions including lower efficacy or overdose of some drugs. Although most DDIs do not lead to significant clinical consequence they sometimes cause complications leading to hospitalization or even death [3, 4].

Between $1.2 \%$ and $9.3 \%$ of the population could be exposed to potential DDIs in outpatient care each year [5-7]. Fluctuations of these estimates mainly depend on the clinical relevance of the DDIs studied and drug interaction database considered. This risk is higher for people exposed to polypharmacy, including the elderly [6, 7]. Prevalence of exposure to DDI in outpatient care was often estimated for one period, without reporting trends over time [5-9]. Moreover, studies have often reported results for the most common DDIs [7, 10] without presenting reusable methods to monitor any targeted DDI.

Administrative health data constitute a valuable resource for conducting pharmacoepidemiological studies, as they reflect routine healthcare utilization for large and representative populations [11-13]. Moreover, long term followup periods allow the study of temporal trends and the effects of health policies. Administrative databases also offer the advantage to be readily available and at a relatively low cost.

The aim of this study was to estimate the yearly prevalence of exposure to potential DDIs in France, using data from a French healthcare insurance system database including $1 / 97^{\text {th }}$ of the French population (Echantillon généraliste de bénéficiaires) from 2006 to 2016, for six DDIs with diverse profiles of prevalence, risk and seriousness of clinical consequences.

\section{Methods}

\section{Data source and design}

The ‘Echantillon généraliste de Bénéficiaires' (EGB) is a 1/97th dynamic random sample of the French population covered by the French healthcare insurance system, corresponding to more than 700000 individuals. At the creation in 2005, only the beneficiaries of the main insurance scheme were included (general scheme, covering $76 \%$ of the French population). The EGB was progressively enriched by the inclusion of all national insurance schemes [14]. The EGB constitutes a representative sample of the French population regarding age, gender, geographical location and healthcare utilization [14]. It contains information on individuals (age, gender) and 
health care reimbursement data, including all outpatient healthcare reimbursements by the French healthcare insurance system. Outpatient reimbursement data cover all drugs prescribed by a healthcare professional, dispensed by community pharmacies and reimbursed by the healthcare insurance system (over-the-counter drugs dispenses are not recorded by definition) [12]. Drugs are identified by their CIP code (drug identification number issued at marketing authorization) with information on the number of units and dosage. For each reimbursed drug, date of prescribing, date of dispensing and information on the prescriber are available. Drugs were classified according to the Anatomical Therapeutic and Chemical (ATC) systemic classification.

\section{Study population}

This retrospective study was conducted from January $1^{\text {st }} 2006$ to December $31^{\text {th }} 2016$. The study population was defined by year concerning all individuals included in the EGB, living in France, alive at the $1^{\text {st }}$ of January or born in the year.

\section{Selection of the studied drug-drug interactions}

An expert committee of the French National Agency for Medicines and Health Products Safety (ANSM) has produced a drug interactions thesaurus [15]. This thesaurus contains pairs of interacting drug substances or classes associated with clinical relevance using four categories (Contraindicated, Not recommended, Precaution for use, To be taken into account). We supposed that each DDI involve an "object" drug, the affected drug, often prescribed for a chronic condition and a "precipitant" drug, the affecting drug, often prescribed for an acute illness [16].

Six DDIs were selected from this thesaurus with various profiles in terms of volume, frequency and potential seriousness of the adverse reaction resulting from the interaction. The following DDIs were studied: angiotensin II receptor blockers or angiotensin-converting enzyme inhibitors + nonsteroidal anti-inflammatory drugs (ARBsACEIs + NSAIDs), antiplatelet agents + NSAIDs (AAP + NSAIDs), oral anticoagulant + NSAIDs (OAC + NSAIDs), serotonergic drugs + tramadol, statins + macrolides and colchicine + macrolides (Table 1). For each DDI, we selected the related ATC codes, removing those corresponding to drugs restricted to inpatient use (not available in the EGB database) (Table S1).

\section{Exposure to potential drug-drug interaction and prevalence estimation}

The period of exposure to one drug class (defined according to ATC codes) was assumed to begin from the day of drug dispensing. The duration of exposure was estimated using the Defined Daily Dose (DDD) and drugs packaging (number of units per box and unit dosage) [16-18]. When the DDD was not available in the ATC/DDD Index, it was determined by the authors' consensus (Table S1). We assumed that patients were exposed to the dispensed drugs for the entire period. 
An episode of exposure to a potential DDI was defined by a continuous period of overlapping exposures of two interacting drugs over at least one day (concomitant exposure). Among the episodes of exposure to DDIs we reported the proportion of episodes with co-prescription, i.e where the two interacting drugs were prescribed by the same physician and dispensed by the same pharmacy the same day [19].

Prevalence of exposure to potential DDIs was estimated by year as the number of individuals (irrespective of their number of yearly exposures) exposed to a potential DDI divided by the study population. To take into account possible changes in drug use over time (related to changes in recommendations for example), we studied two other denominators: (1) individuals with at least one dispensation of one of the object drugs included in the DDI, and (2) individuals with at least one dispensation of one of the precipitant drugs included in the DDI. Prevalence rates were also estimated for four age groups (0-19 years (y), 20-44 y, 45-64 y, 65-84 y and $\geq 85$ y) within the age specific subsample. The $95 \%$ confidence intervals $(95 \% \mathrm{CI})$ were estimated using normal approximation.

\section{Ethics}

National Institute for Health and Medical Research (INSERM) agreement for the research protocol was given in 2017-11-15. Neither ethics committee authorisation nor request to national commissions for individual data protection is required according to French law to access this kind of anonymous and restricted access database. Access to EGB is possible only through a secured connection to a specific server. Data are accessible online, and are analysed by the software SAS Enterprise Guide version 4.3 (Copyright @ 2006 - 2010, SAS Institute Inc., Cary, NC, USA).

\section{Results}

The study population increased from 504255 individuals in 2006 ( $0.80 \%$ of the French population) to 694488 in 2016 (1.05\% of the French population).

In 2016, the number of episodes of exposure to the six selected potential DDIs varied from 71613 for ARBsACEIs + NSAIDs to 175 for colchicine + macrolides, involving from 25458 to 136 distinct individuals respectively (Table 2). The proportions of co-prescription (i.e. the two interacting drugs prescribed by the same physician and dispensed by the same pharmacy the same day) among the episodes of exposure were $58.2 \%$ for serotonergic drugs + tramadol, $42.6 \%$ for AAP + NSAIDs, $40.1 \%$ for ARBs-ACEIs + NSAIDs, $31.8 \%$ for OAC + NSAIDs, $30.3 \%$ for colchicine + macrolides, and $26.2 \%$ for statins + macrolides.

The mean number of episodes by individual exposed at least once to the DDI in 2016 varied from 3.9 for serotonergic drugs + tramadol to 1.3 for colchicine + macrolides. Moreover, the mean duration of one episode ranged from 16 days for ARBs-ACEIs + NSAIDs to 5 days for colchicine + macrolides or serotonergic drugs + tramadol (Table 2). 
Prevalence rates of exposure to DDIs in 2016 was estimated at 3.7\% (95\% CI [3.6;3.7]) of the population for ARBs-ACEIs+NSAIDs, $1.52 \%(95 \%$ CI $[1.49 ; 1.55])$ for AAP+NSAIDs, $0.76 \%(95 \%$ CI $[0.74 ; 0.78])$ for serotonergic drugs + tramadol, $0.36 \%(95 \% \mathrm{CI}[0.35 ; 0.38])$ for statins + macrolides, $0.24 \%(95 \% \mathrm{CI}[0.22 ; 0.25])$ for OAC+NSAIDs and $0.020 \%(95 \%$ CI [0.016;0.023]) for colchicine + macrolides (Table 2).

Trends of prevalence of exposure from 2006 to 2016 are reported in Figure 1. Prevalence of four DDIs increased between 2006 and 2016: $+38.8 \%$ for OAC + NSAIDs, $+34.8 \%$ for serotonergic drugs + tramadol, $+14.7 \%$ for ARBs-ACEIs + NSAIDs and $+13.2 \%$ for AAP + NSAIDs; while the two other DDIs decreased: $-21.0 \%$ for statins + macrolides and $-4.1 \%$ for colchicine + macrolides.

Prevalence rates by age groups were lower for the 0-19 and 20-44 y and higher for the people aged 65 years and over (Figure 2). In 2016, for colchicine + macrolides and for serotonergic drugs + tramadol, the elderly ( $\geq 85$ y) were the most affected age group (prevalence at 0.07\% (95\% CI $[0.04 ; 0.11])$ and $1.89 \%$ (95\% CI [1.72;2.06]), respectively). For the four others DDIs, in 2016, the prevalence was higher for the 65-84 y age group: $11.07 \%$ (95\% CI [10.88;11.25]) for ARBs-ACEIs + NSAIDs, 5.33\% (95\% CI [5.19;5.46]) for AAP + NSAIDs, $1.23 \%$ (95\% CI [1.16;1.29]) for statins + macrolides and 0.85\% (95\% CI [0.80;0.90]) for OAC + NSAIDs.

When considering populations exposed to object drugs or precipitant drugs as the denominator, prevalence rates were higher (Table 2). Prevalence considering population exposed to object drugs as the denominator were decreasing during the study period, except for serotonergic drugs + tramadol (Figure S1). Conversely, prevalence considering population exposed to precipitant drugs as denominator were increasing between 2006 and 2016 except for serotonergic drugs + tramadol (Figure S2).

\section{Discussion}

This study proposed a method to quantify the prevalence of exposure to a potential DDI using administrative data of about $1 \%$ of the French population (EGB). We presented estimates between 2006 and 2016 for six DDIs with various profiles. Exposure to potential DDIs is not uncommon with a high proportion resulting from a coprescription. Trends were changing over time with various patterns.

Making direct comparisons with previous studies that estimated the prevalence of exposure to DDIs in outpatient care is difficult, due to the absence of standardized framework [5-10, 20, 21]. Indeed, study periods varied from a few months $[7,9,10,20]$ to one or several years $[5,6,8,21]$. Also, different denominators in prevalence estimates were used: whole study population [5-7, 10], patients with two or more prescriptions during the study period [9], patients exposed to polypharmacy $[8,21]$ or total number of prescriptions in the study data $[8,10,21]$. Moreover, prevalence estimates were often provided for all DDIs included in the national interaction thesaurus, which greatly differ between countries $[6,9,10,21]$. However, a noticeably high prevalence were reported in the general 
population: 8.5\% over 20 month in Italy [7], 9.3\% in 2015 in Slovenia [6], 4\% on average over 4 months in France [10] and $1.3 \%$ in 2010 in Switzerland [5]. We applied here the same methodology for estimating the prevalence and interpreting the temporal trend of exposure to several DDI, easily replicable with any drugs dispensing reimbursement database.

Consistent with previous studies [6-8], we observed that prevalence was higher among the elderly ( $\geq 65 \mathrm{y})$, in line with their greater exposure to polypharmacy [22]. Depending on the DDIs, the prevalence for the 65-84 y age group were higher than the $85 \mathrm{y}$ and older, as previously reported [7], possibly reflecting age-related prescribing patterns (avoidance of NSAIDs in the elderly for example).

Co-prescription represented between 26 and $58 \%$ of the episodes of exposure to DDI, even for DDI with high clinical relevance. These values are lower than the $70.7 \%$ estimated in an Italian study [7]. Co-prescription may reflect a lack of pharmacological knowledge or a careful choice with diligent instructions and recommendations to the patient. In the case of co-prescription, two health professionals (prescriber and pharmacist) are encountered by the patient. Although automated DDIs alerts could help health care professionals to identify potential DDIs, computerized patient management systems are not routinely used, decreasing the ability to detect potential DDIs $[23,24]$. In addition, warnings are often overridden $[25,26]$.

The database used here allowed studying trends of prevalence over time, considering several denominators. The prevalence of exposure to a DDI is the product of the number of patients receiving the object drug by the conditional probability of them receiving the precipitant drug. The probability of receiving the precipitant drug given an exposure to the object drug depends: (i) of the frequency of use of the precipitant drug and (ii) of the prescriber awareness to the risk of DDI. Interpretation of time trends of prevalence of exposure to DDIs has to take into account the trends of these components. Indeed, we observed that DDIs involving NSAIDs were increasing when considering the total population, but decreasing when we considered the population receiving the object drug as the denominator. This reflected a global increase in the number of people receiving the object drug (ARBs-ACEIs, AAP, and OAC) - possibly linked to ageing population, and a relative decrease of the concomitant exposure to NSAIDs in these patients - perhaps linked to a better consideration of potentially interacting drugs. The two DDIs involving macrolides were decreasing over time, which could be linked to the decrease of the prescription of macrolides [27] and perhaps to a better consideration of interacting drugs possibly due to public health authorities' safety guidelines. Prevalence of the DDI involving serotonergic drugs + tramadol increased sharply from 2006 to 2011 and then decreased (Figure 1). This trend is linked to the gradual reduction until the definitive withdrawal of dextropropoxyphen in France in 2009 leading to a partial switch to tramadol [28, 29]. The decrease in prevalence since 2012 is likely due to national authorities guidelines recommending a switch to paracetamol, published later in 2011 [29, 30]. This shape is also observed when considering the population 
receiving serotonergic drugs as the denominator (Figure S1), suggesting a steady misreading of the DDI involving serotonergic drugs + tramadol.

The main strengths of our study is the exhaustiveness and representativeness of the data used, making the EGB a particularly appropriate tool for conducting pharmacoepidemiological studies with longitudinal follow-up [12]. As the insurance system beneficiaries are included in the EGB whether or not they use care, this database allows prevalence estimates among the general population. In addition, the large number of included beneficiaries results in producing accurate estimates, except for very rare events [14].

Our study has several limitations. As drug dispensations data were used here, we had no direct measure of drug consumptions or treatment adherence, which could lead to overestimate the risk of DDI. On the opposite, overthe-counter drugs (ibuprofen and acetylsalicylic acid can be purchased without a prescription in France) and drugs dispensed in hospitals and some nursing homes were not available, which might have resulted in underestimating the prevalence of DDIs. Periods of exposure to drugs were defined using the DDD, which is only an approximate estimate of the prescribed daily dose. In addition, we considered that all drugs dispensed were used (no leftover pills). As a consequence, the number and duration of episodes of exposure to DDI could be overestimated. However, we also computed the number of co-prescription which corresponds to a more specific definition of exposure to DDIs [19]. We also considered a potential DDI with an overlap of at least one day, but according to half-life of some drugs, a DDI can occur without overlapping, for drugs with long half-life or with pro-drug with one of their metabolite involved in the potential DDI; in an opposite, the potential DDI may have a clinical impact only after a sustained exposure (days or weeks). Finally, we investigated the prevalence of simultaneous exposure to two drugs that could interact, but not of the occurrence of the adverse events possibly related to the DDI, neither the factor associated with the prescription of the drugs involved in the interaction.

The method presented here allowed quantifying exposure to DDIs in the overall population and studying trends over time. Monitoring the prevalence of exposure to DDIs in population is needed to evaluate the impact of prevention measures. Furthers research is needed to estimate the risk of adverse events related to exposure to DDI.

\section{Declarations}

\section{Funding}

This project has received funding from the French National Agency for Medicines and Health Products Safety (ANSM, \#AAP-2017-059). This publication represents the views of the authors and does not necessarily represent the opinion of the ANSM. 


\section{Conflicts of interest/Competing interests}

The authors declare that they have no conflict of interest.

\section{Availability of data and material}

The data that support the findings of this study are available from third party (data owner). Restrictions apply to the availability of these data, which were used under license for this study. Data are available from the authors with the permission of third party.

\section{Authors contribution}

Study concept and design: MLM, TH, OS, LR, TB. Analysis: CS, TL, AMV. All authors participated in the interpretation of the results, drafting and reviewing the manuscript, and approved the final version.

Figures
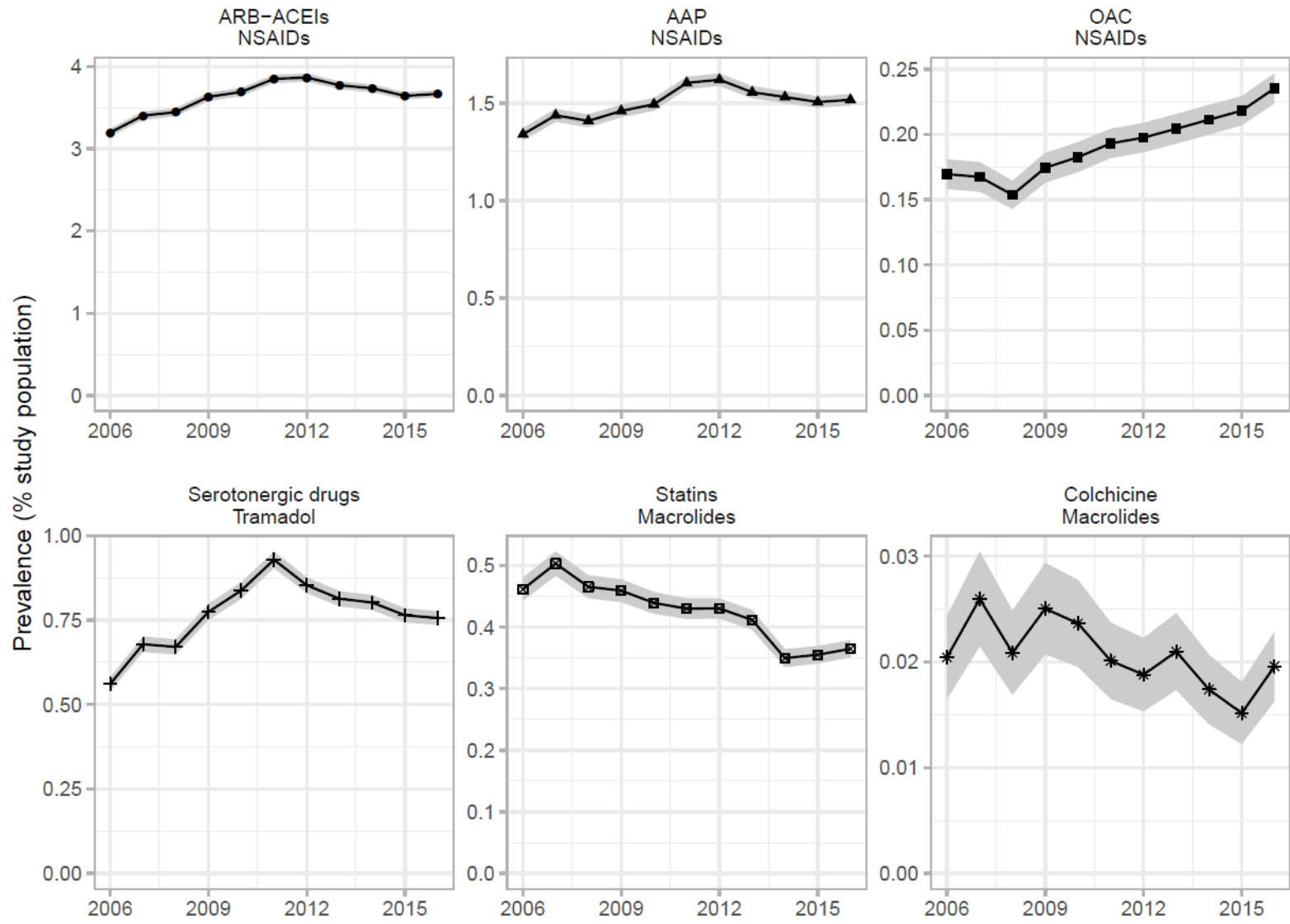

Figure 1. Prevalence and $95 \%$ confidence interval of exposure to six drug-drug interactions between 2006 and 2016 in France

ARBs: angiotensin II receptor blockers; ACEIs: angiotensin-converting enzyme inhibitor(s); NSAIDs: nonsteroidal anti-inflammatory drugs; OAC: oral anticoagulant; AAP: antiplatelet agents 

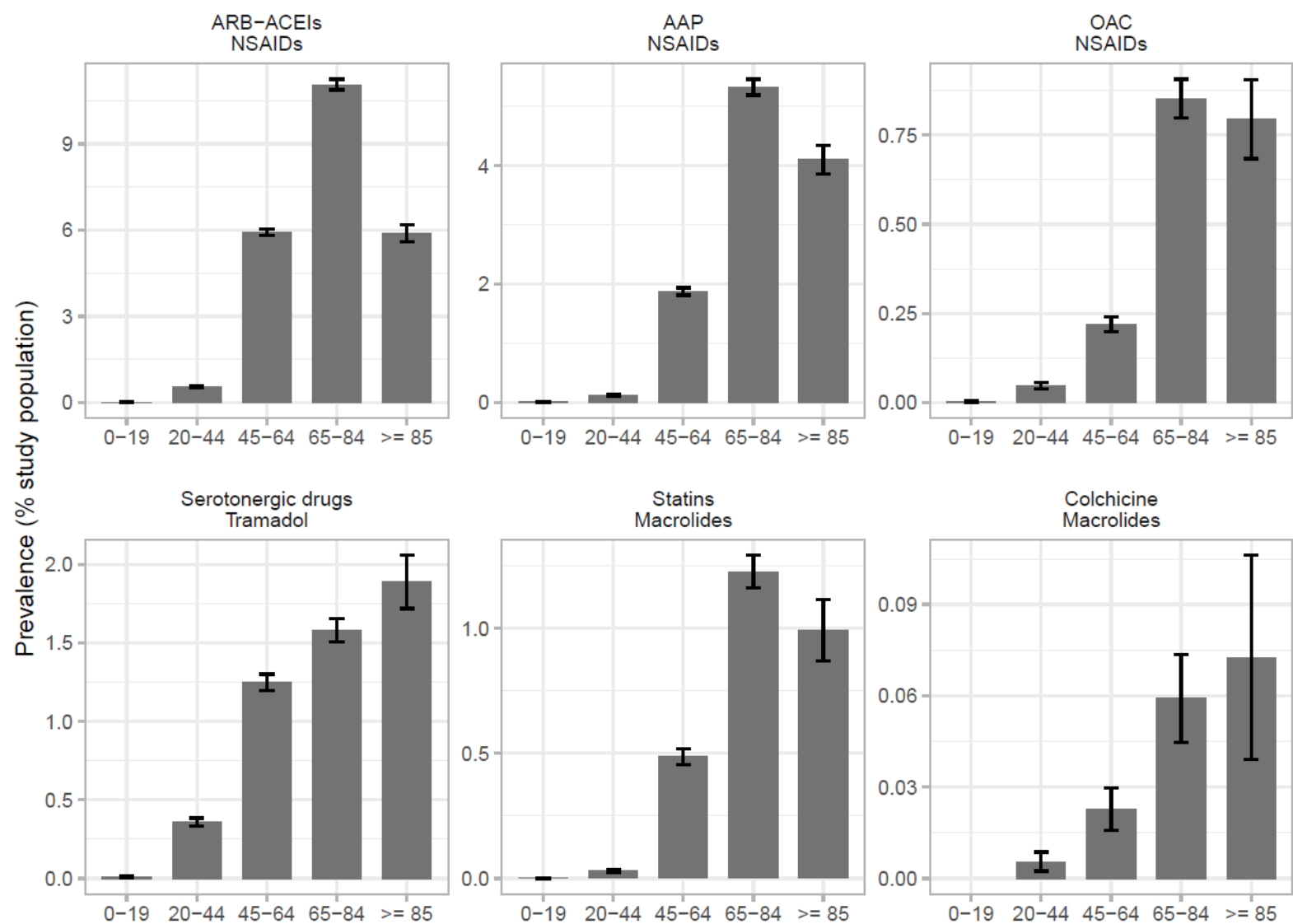

Figure 2. Prevalence and 95\% confidence interval of exposure to six drug-drug interactions by age groups in 2016 in France

ARBs: angiotensin II receptor blockers; ACEIs: angiotensin-converting enzyme inhibitor(s); NSAIDs: nonsteroidal anti-inflammatory drugs; OAC: oral anticoagulant; AAP: antiplatelet agents 


\section{Tables}

Table 1. Drug-drug interactions studied from the French drugs interactions thesaurus (French National Agency

for Medicines and Health Products Safety, ANSM, 2018)

\begin{tabular}{|c|c|c|c|c|c|}
\hline $\begin{array}{l}\text { Drug-drug } \\
\text { interaction }\end{array}$ & $\begin{array}{l}\text { Clinical } \\
\text { relevance }\end{array}$ & 'Object'drugs & 'Precipitant' drugs & $\begin{array}{l}\text { Biological } \\
\text { consequence }\end{array}$ & $\begin{array}{l}\text { Possible } \\
\text { adverse event }\end{array}$ \\
\hline $\begin{array}{l}\text { ARBs-ACEIs } \\
+ \text { NSAIDs }\end{array}$ & $\begin{array}{l}\text { Precaution for } \\
\text { use }\end{array}$ & $\begin{array}{l}\text { ARBs (azilsartan, } \\
\text { candesartan cilexetil, } \\
\text { eprosartan, irbesartan, } \\
\text { losartan, olmesartan, } \\
\text { telmisartan, valsartan) or } \\
\text { ACEls (benazepril, } \\
\text { captopril, cilazapril, } \\
\text { enalapril, fosinopril, } \\
\text { lisinopril, moexipril, } \\
\text { perindopril tert- } \\
\text { butylamine, quinapril, } \\
\text { ramipril, trandolapril, } \\
\text { zofenopril) }\end{array}$ & $\begin{array}{l}\text { NSAIDs (aceclofenac, } \\
\text { mefenamic acid, niflumic } \\
\text { acid, tiaprofenic acid, } \\
\text { alminoprofene, celecoxib, } \\
\text { dexketoprofen, diclofenac, } \\
\text { etodolac, etoricoxib, } \\
\text { fenoprofen, flurbiprofen, } \\
\text { ibuprofen, indometacin, } \\
\text { ketoprofen, meloxicam, } \\
\text { morniflumate, } \\
\text { nabumetone, naproxen, } \\
\text { nimesulide, parecoxib, } \\
\text { piroxicam, rofecoxib, } \\
\text { sulindac, tenoxicam, } \\
\text { valdecoxib) }\end{array}$ & $\begin{array}{l}\text { Glomerular } \\
\text { filtration } \\
\text { decrease }\end{array}$ & $\begin{array}{l}\text { Acute renal } \\
\text { failure }\end{array}$ \\
\hline $\begin{array}{l}\text { OAC + } \\
\text { NSAIDs }\end{array}$ & $\begin{array}{l}\text { Not } \\
\text { recommended }\end{array}$ & $\begin{array}{l}\text { OAC (acenocoumarol, } \\
\text { apixaban, dabigatran, } \\
\text { fluindione, phenindione, } \\
\text { rivaroxaban, warfarin) }\end{array}$ & $\begin{array}{l}\text { NSAIDs (aceclofenac, } \\
\text { mefenamic acid, niflumic } \\
\text { acid, tiaprofenic acid, } \\
\text { alminoprofene, celecoxib, } \\
\text { dexketoprofen, diclofenac, } \\
\text { etodolac, etoricoxib, } \\
\text { fenoprofen, flurbiprofen, } \\
\text { ibuprofen, indometacin, } \\
\text { ketoprofen, meloxicam, } \\
\text { morniflumate, } \\
\text { nabumetone, naproxen, } \\
\text { nimesulide, parecoxib, } \\
\text { piroxicam, rofecoxib, } \\
\text { sulindac, tenoxicam, } \\
\text { valdecoxib) }\end{array}$ & $\begin{array}{l}\text { Gastroduodenal } \\
\text { mucosa damage }\end{array}$ & $\begin{array}{l}\text { Gastrointestinal } \\
\text { hemorrhage }\end{array}$ \\
\hline $\begin{array}{l}\text { AAP + } \\
\text { NSAIDs }\end{array}$ & $\begin{array}{l}\text { To be taken into } \\
\text { account }\end{array}$ & $\begin{array}{l}\text { AAP (acetylsalicylic acid, } \\
\text { clopidogrel, prasugrel, } \\
\text { ticagrelor, ticlopidine) }\end{array}$ & $\begin{array}{l}\text { NSAIDs (aceclofenac, } \\
\text { mefenamic acid, niflumic } \\
\text { acid, tiaprofenic acid, } \\
\text { alminoprofen, celecoxib, } \\
\text { dexketoprofen, diclofenac, } \\
\text { etodolac, etoricoxib, } \\
\text { fenoprofen, flurbiprofen, } \\
\text { ibuprofen, indometacin, } \\
\text { ketoprofen, meloxicam, } \\
\text { morniflumate, } \\
\text { nabumetone, naproxen, } \\
\text { nimesulide, parecoxib, } \\
\text { piroxicam, rofecoxib, } \\
\text { sulindac, tenoxicam, } \\
\text { valdecoxib) }\end{array}$ & $\begin{array}{l}\text { Gastroduodenal } \\
\text { mucosa damage }\end{array}$ & $\begin{array}{l}\text { Gastrointestinal } \\
\text { hemorrhage }\end{array}$ \\
\hline
\end{tabular}


Macrolides (azithromycin,

clarithromycin,

Colchicine + Contraindication Colchicine
Macrolides

erythromycin, josamycin,

Impaired

Rhabdomyolysis

midecamycin,

roxithromycin,

colchicine

and colchicine

telithromycin)

clearance

poisoning

Macrolides (clarithromycin,

Statins $+\quad$ Precaution for

Macrolides $^{\mathrm{a}}$ use

Pravastatin

Simvastatin

Atorvastatine

Contraindication

\begin{tabular}{ll}
\hline Serotonergic & \\
drugs + & Contraindication \\
Tramadol &
\end{tabular}

Not

recommended

o be taken into account

oxidase inhibitors

(iproniazid) erythromycin)

Macrolides (azithromycin,

roxithromycin)

Macrolides (azithromycin Impaired statin

clarithromycin,

clearance

Rhabdomyolysis

and acute renal

failure erythromycin,

roxithromycin)

Telithromycin

Irreversible Monoamine

Reversible inhibitors of

monoamine oxidase $A$

(linezolid, moclobemide)

Inhibitors of monoamine

oxidase B (rasagiline,

Tramadol

Increased

serotonin

reuptake

Serotonin

selegiline) or selective

inhibition

syndrome

serotonin reuptake

inhibitor (citalopram,

escitalopram, fluoxetine,

fluvoxamine, paroxetine,

sertraline, vortioxetin) or

venlafaxine

${ }^{a}$ In the analyses, interactions between the three statins and the five macrolides were considered

ARBs: angiotensin II receptor blockers; ACEIs: angiotensin-converting enzyme inhibitor(s); NSAIDs:

nonsteroidal anti-inflammatory drugs; OAC: oral anticoagulant; AAP: antiplatelet agents 
Table 2. Prevalence and number of exposure to six drug-drug interactions in 2016, Echantillon généraliste de bénéficiaires - EGB, France

\begin{tabular}{|c|c|c|c|c|c|c|c|c|}
\hline & $\begin{array}{l}\text { Number of } \\
\text { episodes of } \\
\text { exposure } \\
\text { to the DDI }\end{array}$ & $\begin{array}{l}\text { Episodes } \\
\text { resulting } \\
\text { from co- } \\
\text { prescription } \\
\quad *(\%) \\
\end{array}$ & $\begin{array}{l}\text { Number of } \\
\text { individuals } \\
\text { exposed to } \\
\text { the DDI }\end{array}$ & $\begin{array}{c}\text { Mean } \\
\text { number of } \\
\text { episodes } \\
\text { per } \\
\text { individual } \\
\text { exposed to } \\
\text { the DDI } \\
\text { during the } \\
\text { year }\end{array}$ & $\begin{array}{l}\text { Mean } \\
\text { duration } \\
\text { of each } \\
\text { episode } \\
\text { (days) }\end{array}$ & $\begin{array}{c}\text { Prevalence } \\
\text { of exposure } \\
\text { to the DDI, } \\
\text { reported to } \\
\text { the } \\
\text { population } \\
\text { exposed to } \\
\text { the object } \\
\text { drugs (\%) }\end{array}$ & $\begin{array}{l}\text { Prevalence } \\
\text { of exposure } \\
\text { to the DDI, } \\
\text { reported to } \\
\text { the } \\
\text { population } \\
\text { exposed to } \\
\text { the } \\
\text { precipitant } \\
\text { drugs }(\%) \\
\end{array}$ & $\begin{array}{l}\text { Prevalence } \\
\text { of exposure } \\
\text { to the DDI, } \\
\text { reported to } \\
\text { all the study } \\
\text { population } \\
(\%) \\
\end{array}$ \\
\hline $\begin{array}{l}\text { ARBs-ACEIs + } \\
\text { NSAIDs }\end{array}$ & 71613 & 40.1 & 25458 & 2.8 & 16 & $\begin{array}{c}29.1 \\
{[28.8 ; 29.4]}\end{array}$ & $\begin{array}{c}11.4 \\
{[11.3 ; 11.5]}\end{array}$ & $\begin{array}{c}3.7 \\
{[3.6 ; 3.7]}\end{array}$ \\
\hline $\begin{array}{l}\text { AAP + } \\
\text { NSAIDs }\end{array}$ & 27504 & 42.6 & 10532 & 2.6 & 14 & $\begin{array}{c}22.1 \\
{[21.7 ; 22.5]}\end{array}$ & $\begin{array}{c}4.7 \\
{[4.6 ; 4.8]}\end{array}$ & $\begin{array}{c}1.52 \\
{[1.49 ; 1.55]}\end{array}$ \\
\hline $\begin{array}{l}\text { Serotonergic } \\
\text { drugs }+ \\
\text { Tramadol }\end{array}$ & 20672 & 58.2 & 5251 & 3.9 & 15 & $\begin{array}{c}13.1 \\
{[12.8 ; 13.4]}\end{array}$ & $\begin{array}{c}9.1 \\
{[8.9 ; 9.3]}\end{array}$ & $\begin{array}{c}0.76 \\
{[0.74 ; 0.78]}\end{array}$ \\
\hline $\begin{array}{l}\text { Statins + } \\
\text { Macrolides }\end{array}$ & 3500 & 26.2 & 2534 & 1.4 & 8 & $\begin{array}{c}5.1 \\
{[4.9 ; 5.3]}\end{array}$ & $\begin{array}{c}6.2 \\
{[6.0 ; 6.5]}\end{array}$ & $\begin{array}{c}0.36 \\
{[0.35 ; 0.38]}\end{array}$ \\
\hline $\begin{array}{l}\text { OAC + } \\
\text { NSAIDs }\end{array}$ & 3222 & 31.8 & 1634 & 2.0 & 13 & $\begin{array}{c}9.0 \\
{[8.6 ; 9.4]}\end{array}$ & $\begin{array}{c}0.73 \\
{[0.70 ; 0.77]}\end{array}$ & $\begin{array}{c}0.24 \\
{[0.22 ; 0.25]}\end{array}$ \\
\hline $\begin{array}{l}\text { Colchicine + } \\
\text { Macrolides }\end{array}$ & 175 & 30.3 & 136 & 1.3 & 8 & $\begin{array}{c}2.3 \\
{[1.9 ; 2.7]}\end{array}$ & $\begin{array}{c}0.28 \\
{[0.24 ; 0.33]}\end{array}$ & $\begin{array}{c}0.020 \\
{[0.016 ; 0.023]}\end{array}$ \\
\hline
\end{tabular}

* Episodes of exposure to the DDI where the two interacting drugs were prescribed by the same physician and dispensed by the same pharmacy the same day

ARBs: angiotensin II receptor blockers; ACEIs: angiotensin-converting enzyme inhibitor(s); NSAIDs: nonsteroidal anti-inflammatory drugs; OAC: oral anticoagulant; AAP: antiplatelet agents 


\section{References}

1. McDonnell PJ, Jacobs MR. Hospital admissions resulting from preventable adverse drug reactions. Ann Pharmacother. 2002;36(9):1331-6.

2. Oertle M. Frequency and nature of drug-drug interactions in a Swiss primary and secondary acute care hospital. Swiss Med Wkly. 2012;142:w13522.

3. Pedros C, Formiga F, Corbella X, Arnau JM. Adverse drug reactions leading to urgent hospital admission in an elderly population: prevalence and main features. Eur J Clin Pharmacol. 2016;72(2):219-26.

4. Becker ML, Kallewaard M, Caspers PW, Visser LE, Leufkens HG, Stricker BH. Hospitalisations and emergency department visits due to drug-drug interactions: a literature review. Pharmacoepidemiol Drug Saf. 2007;16(6):641-51.

5. Bucher HC, Achermann R, Stohler N, Meier CR. Surveillance of Physicians Causing Potential DrugDrug Interactions in Ambulatory Care: A Pilot Study in Switzerland. PLoS One. 2016;11(1):e0147606.

6. Jazbar J, Locatelli I, Horvat N, Kos M. Clinically relevant potential drug-drug interactions among outpatients: A nationwide database study. Res Social Adm Pharm. 2018;14(6):572-80.

7. Tragni E, Casula M, Pieri V, et al. Prevalence of the prescription of potentially interacting drugs. PLoS One. 2013;8(10):e78827.

8. Bjerrum L, Andersen M, Petersen G, Kragstrup J. Exposure to potential drug interactions in primary health care. Scand J Prim Health Care. 2003;21(3):153-8.

9. Astrand B, Astrand E, Antonov K, Petersson G. Detection of potential drug interactions - a model for a national pharmacy register. Eur J Clin Pharmacol. 2006;62(9):749-56.

10. Letinier L, Cossin S, Mansiaux Y, et al. Risk of Drug-Drug Interactions in Out-Hospital Drug Dispensings in France: Results From the DRUG-Drug Interaction Prevalence Study. Front Pharmacol. 2019;10:265.

11. Harpe SE. Using secondary data sources for pharmacoepidemiology and outcomes research. Pharmacotherapy. 2009;29(2):138-53.

12. Palmaro A, Moulis G, Despas F, Dupouy J, Lapeyre-Mestre M. Overview of drug data within French health insurance databases and implications for pharmacoepidemiological studies. Fundam Clin Pharmacol. 2016;30(6):616-24.

13. Schneeweiss S, Avorn J. A review of uses of health care utilization databases for epidemiologic research on therapeutics. J Clin Epidemiol. 2005;58(4):323-37.

14. Tuppin P, Rudant J, Constantinou P, et al. Value of a national administrative database to guide public decisions: From the systeme national d'information interregimes de l'Assurance Maladie (SNIIRAM) to the systeme national des donnees de sante (SNDS) in France. Rev Epidemiol Sante Publique. 2017;65 Suppl 4:S149s67.

15. Agence nationale de sécurité du médicament et des produits de santé. Thesaurus des interactions médicamenteuses. March 2018.

16. Hennessy S, Leonard CE, Gagne JJ, et al. Pharmacoepidemiologic Methods for Studying the Health Effects of Drug-Drug Interactions. Clin Pharmacol Ther. 2016;99(1):92-100.

17. WHO Collaborating centre for Drug Statistics Methodology. Defined daily dose: definition and general considerations. https://www.whocc.no/ddd/definition_and_general_considera/. Accessed March 28, 2019.

18. WHO Collaborating centre for Drug Statistics Methodology. ATC/DDD Index 2019. https://www.whocc.no/atc ddd_index/. Accessed March 28, 2019.

19. Tobi H, Faber A, van den Berg PB, Drane JW, de Jong-van den Berg LT. Studying co-medication patterns: the impact of definitions. Pharmacoepidemiol Drug Saf. 2007;16(4):405-11.

20. Merlo J, Liedholm H, Lindblad U, et al. Prescriptions with potential drug interactions dispensed at Swedish pharmacies in January 1999: cross sectional study. Bmj. 2001;323(7310):427-8.

21. Linnarsson R. Drug interactions in primary health care. A retrospective database study and its implications for the design of a computerized decision support system. Scand J Prim Health Care. 1993;11(3):1816.

22. Scott IA, Hilmer SN, Reeve E, et al. Reducing inappropriate polypharmacy: the process of deprescribing. JAMA Intern Med. 2015;175(5):827-34.

23. Langdorf MI, Fox JC, Marwah RS, Montague BJ, Hart MM. Physician versus Computer Knowledge of Potential Drug Interactions in the Emergency Department. Acad Emerg Med. 2000;7(11):1321-9.

24. Weideman RA, Bernstein IH, McKinney WP. Pharmacist recognition of potential drug interactions. Am J Health Syst Pharm. 1999;56(15):1524-9.

25. Glassman PA, Simon B, Belperio P, Lanto A. Improving recognition of drug interactions: benefits and barriers to using automated drug alerts. Med Care. 2002;40(12):1161-71.

26. van der Sijs H, Aarts J, Vulto A, Berg M. Overriding of drug safety alerts in computerized physician order entry. J Am Med Inform Assoc. 2006;13(2):138-47. 
27. Adriaenssens N, Coenen S, Versporten A, et al. European Surveillance of Antimicrobial Consumption (ESAC): outpatient macrolide, lincosamide and streptogramin (MLS) use in Europe (1997-2009). J Antimicrob Chemother. 2011;66 Suppl 6:vi37-45.

28. Gaubert S, Vie M, Damase-Michel C, Pathak A, Montastruc JL. Dextropropoxyphene withdrawal from a French university hospital: impact on analgesic drug consumption. Fundam Clin Pharmacol. 2009;23(2):247-52.

29. Hider-Mlynarz K, Cavalie P, Maison P. Trends in analgesic consumption in France over the last 10 years and comparison of patterns across Europe. Br J Clin Pharmacol. 2018;84(6):1324-34.

30. French National Agency for Medicines and Health Products Safety. Prise en charge des douleurs de l'adulte modérée à intenses a http://www.ansm.sante.fr/var/ansm_site/storage/original/application/a6497f74fc2f18e8db0022973f9327e1.pdf.

Published August 4, 2011. Accessed December 20, 2019. 